\title{
ALFRED AGACHE E SEU PLANO PARA CURITIBA: TECNICA, INSTITUCIONALIZAÇÃO E O INICIO DO DISCURSO DA CIDADE PLANEJADA
}

\section{Julio Cesar Botega do Carmo}

Mestre em Geografia pela Universidade Federal do Paraná

\section{Resumo}

Assim como o urbano, os cientistas que tentam explicá-lo são fruto de dado momento histórico e determinados social, política, ideológica, jurídica e economicamente. Com base neste fato e tomando-se as ideias centrais dos intelectuais que através da Geografia Urbana e da Geografia Histórica entendem o espaço, se busca a compreensão da cidade de Curitiba durante o século $X X$, verificando como a abordagem técnico-científica agiu na regulação do crescimento e na modernização, demonstrando como a ciência nos ajuda na compreensão da cidade, neste caso dando especial destaque a uma cidade brasileira e sua realidade de país emergente.

Palavras-chave: Alfred Agache, Urbanismo, Curitiba

\begin{abstract}
Like the urban, scientists trying to explain it are the result of certain historical moment and social, political, ideological, legal and economically. Based on this fact and taking the main ideas of the intellectuals who through the Urban Geography Historical Geography and understand the space, it seeks to understand the city of Curitiba during the twentieth century, looking at how to approach technical- scientific acted in the regulation of growth and modernization, demonstrating how science helps us to understand the city, in this case with particular emphasis on a Brazilian city and its emerging reality of the country.
\end{abstract}

Keywords: Alfred Agache, Urbanism, Curitiba

A história do francês Alfred Agache, colaborador do primeiro plano urbanístico realizado para Curitiba, se confunde com o próprio desenvolvimento do Urbanismo. Utilizando-se do texto de Choay (2007), pode-se afirmar que Alfred Agache se encontra na transição do pré-urbanismo para o urbanismo propriamente dito, sendo uma espécie de híbrido entre o pré-urbanismo progressista e o pré-urbanismo culturalista, tendo como principais referências de vanguarda as intervenções de Ildefonsé Cerdá, em Barcelona, e de Georges- Eugène Haussmann, em Paris.

Donat Alfred Agache nasceu na cidade de Tours em 1875, e faleceu em Paris no 
ano de 1959. Estudou na Escola de Belas Artes de Paris, e lecionou História da Arte no Colégio Livre de Ciências Sociais. Foi por muito tempo secretário geral da Societé Française des Urbanistes (SFU). Elaborou planos de Urbanismo para Paris, Dunquerque, Portiers, Dieppe, Tours, Orleans, Chicago, Lisboa etc. Foi um dos primeiros urbanistas franceses que estudou a formação das cidades, compreendeu e analisou a transformação da arte urbana em Urbanismo através da técnica de planos de ordenamento e de extensão das cidades. (BRUANT, 1996)

Bruant (1996), afirma que é dos estudos combinados de Arquitetura e Sociologia, que resultou o Urbanismo de Agache. O Urbanismo seria assim, uma "Sociologia Aplicada". Agache foi um dos principais arquitetos-urbanistas do século passado, unindo a Arquitetura às Ciências Sociais, entre estas a Geografia. Agache tinha uma visão vitalista e funcionalista da cidade, onde deveriam ser feitas cirurgias, aplicados remédios, sendo o urbanista, o médico gestor das operações, elaborando o diagnóstico, as intervenções cirúrgicas e a dieta a ser seguida, bem como os cuidados estéticos. Para Agache (1930):

A aglomeração urbana é, sem dúvida alguma, uma manifestação física, em todas as dimensões da atividade humana - sempre devendo ser considerada sua relação com a antropogeografia e também principalmente com os fatos sociais. (AGACHE, 1930, s.p.)

Para a busca destas relações, Agache propõe um método, que denomina "Análise Monográfica da Cidade", indo ao encontro do proposto por Monbeig, onde o social e o espacial, o urbano e o humano são examinados, além da história, da origem, da duração, das causas e dos princípios que orientam as Leis de Evolução do fenômeno urbano. Segundo Agache,

Se existem leis de evolução da cidade, o urbanista deverá, queira ou não queira, se conformar a elas. É por isso, que todo estudo urbanístico, escreve ele ainda, deve começar por uma sondagem concreta sistemática do contexto social e urbano da cidade em questão, que as formas construídas devem ser estudadas dentro de sua história e dentro de suas "relações com a antropogeografia e sobre tudo com os fatos sociais": o conjunto constitui o estudo de monografia urbana. ( Agache in: BRUANT, Catherine. Un architecte à I'école d'energie. Donat Alfred Agache, du voyage a I'engagement colonial. In: Figures de I'orientalisme enarchitectura, n. 73/74, 1996, p. 111 apud SILVA, 2000, p. 41)

Agache, definiu a nova ciência desta maneira:

O Urbanismo é uma nova ciência da construção e do planejamento das cidades... É uma ciência de aplicação, pois possui, essencialmente uma utilidade prática: controlar o desenvolvimento e o crescimento das cidades. [..] integra os conhecimentos dos técnicos, do sociólogo, do engenheiro, do legista e sobretudo do higienista ... integra todas as competências e todos os 
saberes.[..] É uma ciência mas também uma arte. (AGACHE, 1930, s.p.)

Para ele,

A palavra Urbanismo, tem que ser ampla e englobar não somente uma técnica especializada, mas, de alguma forma, a própria filosofia da coisa: o Urbanismo não é somente uma arte e uma ciência, é, antes de tudo, uma filosofia social, pois é fato que o econômico e o social intervém nitidamente na criação, no desenvolvimento e na evolução das cidades[..] visto que hoje nos damos conta dos elementos sociais que fazem parte da composição das cidades, que determinam seu nascimento, seu crescimento e sua decadência, e uma meta: curar a cidade doente. (AGACHE, 1930, s.p.)

Agache viveu, compreendeu e analisou a transformação da arte urbana em Urbanismo. A questão urbana como questão social teve lugar destacado em sua formação. Em 1901, publicou na revista La Science Social seus trabalhos de observação de fatos sociais e geografia e suas relações com as artes. No Colégio Livre de Ciências Sociais, em 1905, ministrou dois cursos sobre a evolução e a História Social das Belas-Artes. Para ele, os fatos repercutiam nas obras e vice- versa. Dentro de um pensamento evolucionista e organicista, acreditava que o conhecimento de uma sociedade permitiria determinar o sentido de sua evolução e projetar as mudanças para alcançar sua prosperidade:

O Urbanismo - nós o dissemos frequentemente em nossas conferências - é ao mesmo tempo uma ciência, uma arte e uma filosofia. Uma ciência pois ele procede do estudo metódico dos fatos. É preciso ter estudado as cidades do passado, suas características, sua formação...depois de um trabalho preciso de análise, é necessário, em uma síntese geral, prever os melhoramentos necessários para o desenvolvimento futuro da cidade. (AGACHE, 1930, p. XVIII, v. 1)

O estudo do Urbanismo era caracterizado pela observação, classificação, análise e síntese e o urbanista deveria interpretar proporções, silhuetas, volumes e composição para produzir efeito estético artístico nas cidades. Agache enquadrava o Urbanismo no domínio da Filosofia Social, organizando aglomerações de tal forma que os habitantes pudessem usufruir os benefícios da modernidade a baixos custos. (SILVA, 2000, p. 70)

O urbanismo de Agache incluía um pensamento que oscilava entre ideias positivas de ordem social, relacionando espaço sociais e atividades sociais. O espírito que aproximava o ambiente ao espaço voltava-se para estabelecer uma ordem social através da manipulação do ambiente. O urbanista iniciaria seu contato com o local coletando material escrito e oral. A busca de critérios para coordenar e harmonizar as atividades, adaptando-as ao progresso, dominou o campo de ação do Urbanismo a 
partir do momento em que higiene e estética deixaram de ser os únicos veículos de renovação urbana para operar uma síntese com a função econômica. (SILVA, 2000)

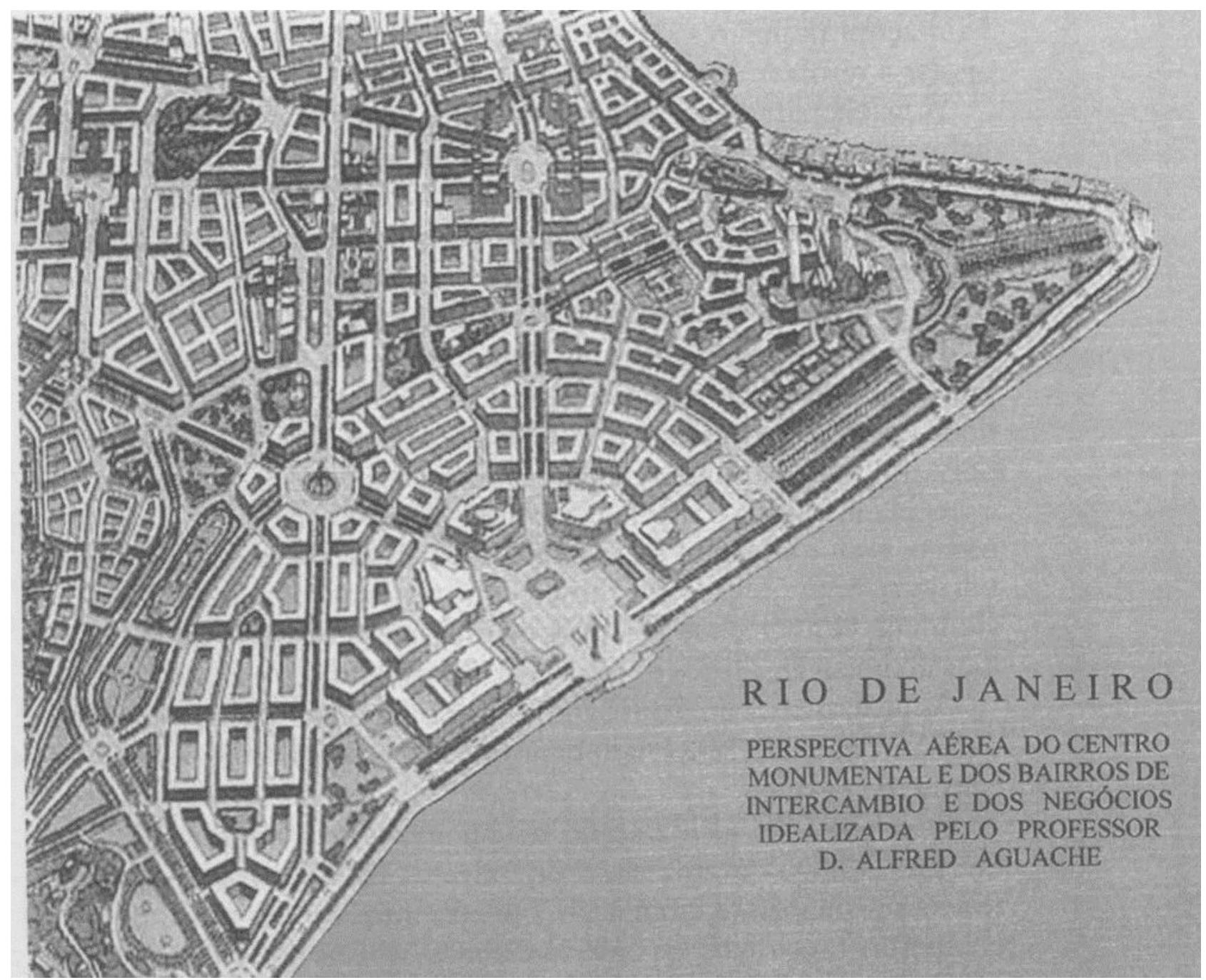

Figura 1: Perspectiva do Plano Agache para o Rio de Janeiro Fonte: AGACHE, 1930

Vê-se no Plano Agache para o Rio de Janeiro (figura 1), a nítida influência dos arquitetos modernistas, da criação e aplicação em cidades de países em vias de desenvolvimento, de pressupostos que não puderam colocar em prática nas cidades europeias e norte-americanas, visto que a crise econômica dos anos 1920 e as Guerras Mundiais limitavam as possibilidades de trabalho na Europa e impelia os profissionais a buscarem novos clientes e mercados. Nas palavras de Pereira (1996):

A América Latina e os territórios coloniais na África, nas três primeiras décadas do século $X X$, acenavam com a possibilidade de experimentação e verificação da pertinência de certas teses e sua difusão, mais tarde, como teorias. Isto permitiria falar numa continuidade desta preeminência francesa em matéria de planejamento urbano até pelo menos a Segunda Guerra[..] Foi, portanto, quase "natural" que os problemas [..] (e o) movimento [..] em prol de um estudo global da cidade acabassem por trazer [..] técnicos 
franceses. Um era "arquiteto-urbanista" saído da tradição do sistema BeauxArts, o outro era "arquiteto" auto-didata e grande polemista na defesa de um "espírito novo": Donat-Alfred Agache e Le Corbusier. (PEREIRA, 1996, pg. 368)

Assim, Agache encontrou no Brasil, especialmente quando convidado para a elaboração do plano do Rio de Janeiro, um local fértil e ávido por modernidade, e apesar das muitas críticas as suas ideias, pessoas que se engajaram em ajudá- lo, o que levou parte daquelas a serem colocadas em prática.

Já em Curitiba, na década de 1930, a organização espacial consistia em políticas para proteger os proprietários de imóveis e não o controle das atividades exercidas sobre o solo. O zoneamento desta época se restringia a estabelecer, sempre que necessário, as divisas das três zonas fiscais, sejam elas urbana, suburbana e do rocio:

ART. $2^{\circ}$ - Compreende a zona urbana, os terrenos que estão situados nas ruas, praças e avenidas, dentro dos limites do quadro urbano da cidade e das povoações do Município.

ART. $3^{\circ}$ - Compreende a zona suburbana a faixa de 1 quilômetro além dos limites do quadro urbano.

ART. $4^{\circ}$ - Compreende o rocio a zona compreendida entre os limites suburbanos e os do município. (Código de Posturas - Capítulo 1 - Lei no 527 de 27 de janeiro de 1919)

$\mathrm{Na}$ primeira zona as construções permitidas eram de casas cujas paredes externas fossem feitas de alvenaria. Casas de madeira podiam ser construídas nas outras duas zonas. Contudo, as edificações eram defeituosas, os arruamentos não seguiam um traçado sanitário, os loteamentos não tinham controle, os terrenos centrais adquiriam um alto valor estimulando a retenção para especulação levando ao movimento da população em direção às periferias. A produção de grandes conjuntos arquitetônicos, a programação rígida de um sistema viário e a especialização de espaços configuraram uma ocupação conflituosa, privilegiando a centralização e deixando a periferia sem um programa de trabalho, serviços e investimentos. (SILVA, 2000, p. 61) A reorganização de Curitiba, dentro dos moldes do Urbanismo então praticado, ampliou o investimento para o capital comercial e agrícola, os quais se voltaram para as construções de imóveis urbanos, e mais tarde, para a efetivação de um processo de industrialização.

Neste momento, o controle das condições de salubridade levou a Prefeitura a contratar o arquiteto carioca Lucas Meylhofer para idealizar um plano de higienização dos rios Ivo e Belém. Ele projetou a retificação e a canalização dos rios, direcionando o crescimento da cidade para o nordeste com a construção de uma avenida radial margeando o rio Belém. Era importante aproveitar os espaços vazios da área, pouco 
valorizados e buscar concretizá-la de imediato. (SILVA, 2000, p. 47) Neste período, a produção e consumo do espaço se transformaram em atividade dos proprietários de terras e pela municipalidade, que tomava iniciativa para atender as necessidades de moradias, dando assistência financeira (doações de terrenos) aos interessados em construir habitações na cidade. Muitos terrenos foram desapropriados e doados a entidades para construção de casas populares. A cidade melhorou seu padrão construtivo enquanto que as condições de urbanização necessitavam um remodelamento, um plano, dizia o discurso da época, pois o plano distribuiria as funções na cidade. (SILVA, 2000, p. 63) Era portanto, para organizar a cidade, necessária a contratação de um plano urbanístico.

Abrangendo aspectos físicos, socioeconômicos e administrativos de uma cidade, um plano urbanístico era visto como instrumento de intervenção do tipotécnico na expansão urbana, proporcionando à cidade a mudança social que traria melhoras nas condições de moradia, de trabalho, de circulação e de lazer, atendendo às funções urbanas e respeitando as aspirações humanas. Era uma intervenção em grande escala que definia um sistema viário, áreas de uso, áreas verdes e equipamentos urbanos. $A$ Curitiba da primeira metade do século XX era vista como um emaranhado de ruas com um conjunto de casas e edifícios e seu crescimento era sem orientação ou planejamento, o que tinha causado problemas de congestionamento. O ritmo de crescimento do número de pessoas, veículos, volume de mercadorias, serviços prestados, empregos, e as pressões sobre o setor habitacional cresceram de forma superior ao do crescimento material e funcional da cidade.

As correlações entre crescimento populacional e expansão territorial apontavam uma incompatibilidade entre dimensão dos problemas e realidade da administração. $\mathrm{Na}$ rua XV de Novembro, os estabelecimentos comerciais pertenciam aos descendentes de imigrantes e as residências passavam por uma fase de transição nos anos 1940. Os velhos solares foram transformados em escritórios e consultórios, e as pequenas casas eram substituídas por modernas construções. Áreas foram sendo ocupadas sem consciência das implicações de adensamento, usos específicos ou mesmo segregação residencial por tamanho de lotes. O poder público foi experimentando os conhecimentos urbanísticos e o complexo trabalho de planejar a cidade como um todo orgânico.

Partindo da Carta de Atenas, a ideia era que a urbanização atua na estrutura da cidade e a função da administração municipal seria a de atender aos reclamos urbanísticos da população, procurando administrar os recursos, as aspirações e as tendências de uma região. A imprensa expressava as inquietações da comunidade 
sem conhecimento direto e objetivo dos problemas que o crescimento da população imprimia à oferta de serviços e que a ordenação do espaço era uma criação contínua. (SILVA, 2000, p. 34) Neste contexto, com a necessidade de um plano urbanístico e de posse da planta cadastral da cidade, a prefeitura contratou a empresa dos irmãos Coimbra Bueno para a formulação de um plano. Com assessoria de Alfred Agache, em aproximadamente dois anos o plano foi entregue. Segundo Garcez (2006)

No final da década de 30, aproveitando a presença no Brasil do famoso urbanista francês Alfred Agache, que orientava a elaboração de planos diretores para diversas cidades, o governo estadual resolveu encomendar um plano para Curitiba.

A motivação básica para o trabalho era, sem dúvida, o saneamento do centro, sujeito aos desastres frequentes das enchentes. Embelezamento, congestionamento ou setorização, itens igualmente constantes da proposta, eram problemas que certamente se agravariam no futuro, mas saneamento era um problema do presente e se esperava soluções por meio de radicais medidas urbanísticas vindas de um dos mais reputados urbanistas europeus, uma vez que as soluções paliativas das tentativas anteriores não foram bem sucedidas. (GARCEZ, 2006, p. 70)

O autor prossegue

O contrato foi firmado em 25 de abril de 1941, compreendendo:

I - Projetos de remodelação, embelezamento e extensão imediata, incluindo plano de avenidas e projetos de remodelação de praças, projeto de estádio e praças de esporte em geral e estudo de tráfego do centro urbano.

II - Estudos complementares, incluindo indicações e previsões do problema do escoamento de águas pluviais e inundações, estudo sobre o sistema de esgoto a ser adotado e abastecimento de água, localização de áreas a serem reservadas para serviços públicos urbanos como escolas, hospitais, limpeza pública, corpo de bombeiros, parque municipal e grande lagoa com cascatas.

III - Regulamentos, como de loteamento e utilização de áreas, fixação de gabaritos zoneamento e código de construções. (GARCEZ, 2006, p. 70 e 71)

Ao contrário de outras cidades, segundo Gnoato (1997), em Curitiba, os planos elaborados desde então não permaneceram no papel, pois a cidade reunia condições favoráveis para implantação de planos, pois se preparava para um crescimento acelerado, possuía condições socioculturais de poucas discussões e modelo econômico, determinado pela política nacional. (GNOATO, 1997, p. 6)

A proposta para a contratação de um plano urbanístico para Curitiba durante a década de 1930 decorria do fato de que em pouco mais de uma década, o estado estaria comemorando o centenário de sua emancipação política da província de São Paulo. Contudo, mesmo quase um século depois de elevada à condição de capital, a cidade mantinha o ar interiorano e provincial, o qual o poder público e a elite estadual queriam acabar por vez, sendo o Urbanismo uma forma de aplicar este caráter moderno à cidade. Para conseguir um plano seria preciso primeiro reorganizar a intervenção urbana e se pensar na cidade toda. Contudo, para alguns autores 
(GARCEZ, 2006) a prefeitura não possuía condições para elaborar o plano, pois faltava-Ihe pessoal especializado, políticas definidas, financiamento, programas e metas. Na contramão deste pensamento, para Cunha Filho (1998) a cidade possuía condições para tal:

Sob os confetes que caem sobre a cidade alguns cientistas sociais têm buscado pelas causas de tanto sucesso. Ao pretenderem investigar o urbanismo curitibano, remontam suas primeiras manifestações à 1943, quando da elaboração do primeiro plano diretor de Curitiba, pelo urbanista francês Alfred Donat Agache. Ora, se o poder público conseguiu implementálo ao longo de uns anos, tanto que hoje ainda se nota suas marcas pela cidade, foi porque possuía maturidade suficiente para fazê-lo. (CUNHA FILHO, 1998, pg. 1)

Possuindo ou não condições para fazê-lo, uma cidade com um plano urbanístico pressupunha hierarquia, organização e controle da ordem. (SILVA, 2000, p. 38) Assim, a contratação do urbanista francês Alfred Agache na década de 1940, envolve uma visão de sua trajetória profissional, pois implantados ou não, seus planos constituem parte de um processo de pensamento e ação urbanística. (SILVA, 2000, p. 39) Um plano urbanístico era um meio de produzir transformações na sociedade, pensava Agache, e ele transmitia suas ideias para Curitiba. Segundo Cunha Filho (1998)

[...] o fator técnico que faltava à Prefeitura e que, decididamente, marcou o fim de um período do moderno urbanismo curitibano, só se fez presente em 1935. Certamente que as condições que delegam o caráter "moderno" ao urbanismo já vinham se manifestando a algum tempo. De fato, o aspecto científico das intervenções, a autoridade estatal da qual eram investidas, bem como sua característica de "permanência" já eram conhecidos. O caráter institucional, porém, que ajuda a compor o fenômeno do urbanismo recente, só veio se confirmar plenamente após a elaboração da Planta Cadastral de Curitiba. (CUNHA FILHO, 1998, pg. 151)

Um plano destacaria as características de um centro urbano para então estabelecer diretrizes e localização das zonas no espaço. No período da Segunda Guerra Mundial, o Urbanismo transformava-se devido às necessidades de defesa e os planos deveriam exprimir essas tendências combatentes na organização de seus centros funcionais. (SILVA, 2000, p. 71; GARCEZ, 2006, p. 77)

O urbanista francês contratado, Agache, era um apreciador de LeandreVaillat, que considerava das principais finalidades do urbanismo "le décor de la vie", e continuador de Haussmann, tendo no primeiro plano de suas preocupações a abertura de avenidas e praças com pontos estratégicos para as

perspectivas em que se imiscuíam conjuntos cenográficos e triunfais. Agache ocupava posição de destaque nos quadros técnicos e políticos franceses, tendo sido chefe das reconstruções das cidades destruídas pela Primeira 
Guerra Mundial ${ }^{1}$. O plano que fez para o Rio de Janeiro foi um exemplo típico do planejamento urbano europeu da época: abrangente, racional, porém, com pressupostos sociais simplificados (figura 4). (GNOATO, 1997, p. 16)



Figura 2: Plano Agache para o Rio de Janeiro, esquema de circulação Fonte: MOREIRA, s.d.

O plano feito por ele contribuiu na criação de ambiente e tradição de Urbanismo e Planejamento Urbano junto aos técnicos da cidade de Curitiba. Seu plano continha o desenho das ruas e de suas interseções; sugestões para praças, e perspectivas para o Centro Cívico, o Estádio Esportivo, a Estação Rodoviária e demais Centros Funcionais. Desta maneira, se passou a dispor de instrumentos para orientar o crescimento, para disciplinar a circulação de veículos e a construção de edifícios.

Como a municipalidade já possuía legislações detalhadas, de origem colonial, Agache reforçou seus mecanismos, compilados em 1953 no Código de Posturas, não tendo sido inteiramente substituídos até os anos de 1990. (GNOATO, 1997, p. 18) Um terço do plano foi dedicado ao problema de saneamento, até hoje não completamente resolvido. Visava modernidade, mas enquanto sinônimo de progresso, expresso em

1 A respeito deste assunto pode-se consultar do urbanista o seguinte livro: AGACHE, Alfred. Comment reconstruire nos cités détruites, notions d'urbanisme s'appliquant aux villes, bourges et villages. Ed. Colin, Paris, 1916. 
obras materiais, mais que em ações de caráter social. Ao observar a inexistência das favelas argumentou que "uma única habitação de favela que apareça será o gérmen e a proliferação deste vírus é espantosa". (BOLETIM PMC, 1943, p. 10)

Ele considerou que seu plano atendia a um futuro imediato e foi o primeiro e talvez único, concebido para Curitiba, pela abrangência e pelas condições do projeto. Na comparação entre o plano e o que foi executado, é perceptível a capacidade de implantação e potencialidade, ao propiciar ambiente a próxima intervenção urbana que aconteceu a partir dos anos de 1970. (GNOATO, 1997, p. 21) Vendo a cidade como um organismo vivo, Agache conseguiu mudar sua história e aparência, redesenhando antigos traçados, criando centros funcionais e estabelecendo novos parâmetros no crescimento territorial. A maior preocupação estava no alargamento das ruas e no desenho das edificações. Se o desenvolvimento da cidade permitisse, provavelmente teriam sido desfeitas quadras do centro, pois, como afirma Gnoato (1997) "a preocupação em manter as construções existentes, que compõem conjunto arquitetônico de determinada época, não estava na ordem do dia dos urbanistas dos anos 40." (GNOATO, 1997, p. 24)

Assim, aos poucos, criou-se a cidade que delineou a configuração atual, onde ruas foram alargadas e o pensamento voltou-se definitivamente para o embelezamento das áreas residenciais e para a preservação das áreas verdes. Para a administração pública, atendendo aos vários interesses que a compõem, tornou-se de suma importância fazer um novo planejamento, que possibilitaria a expansão das áreas de construção e, em especial, a dos prédios de vários andares. Ferreira (2004) escreve que "nesta época foram construídos vários prédios públicos e privados, como também, surgiram as primeiras galerias em alguns edifícios da rua XV de Novembro. Tais construções passaram a ser o orgulho da cidade, representando a grandiosidade e a modernidade tão almejadas" (FERREIRA, 2004, p. 25), revelando a face urbanística do Estado Novo.

Uma das principais metas do Plano Agache era resolver o grave problema de Curitiba ter um centro com tendência ao congestionamento e às enchentes devido aos cursos d'água, motivadores de endemias. O centro era formado por distorções que afetavam todo o sistema viário e os meios de transporte. A organização das perimetrais visava facilitar a circulação intra e interurbana, além de delimitar a expansão da cidade, protegendo a zona de residências. A avenida que seria aberta em locais arborizados, seguindo o modelo americano das parkways estaria articulada com avenidas radiais, que se voltavam para o centro. O anel de entorno ao centro era formado por bairros com ocupação consolidada e a imprensa registrava que as áreas 
formavam um tecido urbano cada vez maior, podendo ser um tecido delimitado por vias. A extensão da cidade ocorreria dentro do perímetro da Avenida Perimetral 3 e o primeiro instrumento era a regulamentação dos arruamentos e loteamentos descritos no Código de Obras. (SILVA, 2000, p. 80)

Para Agache a tendência da cidade era de rápido desenvolvimento, com geração de riquezas bem distribuídas, com poucas possibilidades de formação de bolsões de pobreza como ocorrera na então capital federal, Rio de Janeiro. Imaginou que Curitiba teria que inevitavelmente preparar sua malha viária para atender um tráfego intenso de automóveis e que essa concentração de automóveis exigiria ruas largas, de alta velocidade de escoamento, sem empecilhos como cruzamentos curtos e entrecortados, e permitissem o deslocamento do centro para os bairros. Nasceram dessas premissas, as famosas conectoras e as perimetrais (hoje, conhecidas também como vias expressas ou rápidas). Agache projetou o crescimento de Curitiba rumo aos bairros, liberando o centro curitibano apenas para o comércio e o lazer (centro de eventos: teatros, cinemas, etc.). As avenidas de ligação, desde que dessem rápido acesso bairro- centro, seriam fator de atração para a urbanização da periferia, pois os trabalhadores chegariam ao centro por meio de um sistema geral de transporte de massa.

Para definir os novos traçados da cidade, Agache usou como parâmetros a "eficiência" e a "salubridade". A eficiência se refletiria nas ruas largas e espaços o verde (OBA, 1998). A salubridade estava refletida na preocupação com as grandes concentrações humanas na cidade, o aumento da ocupação irregular e o crescimento no número de "pobres", que atrapalhavam a "visibilidade", daí a ideia de se afastar a população carente dos centros comerciais e moradias das classes com maior poder aquisitivo, que se inspiraram nas intervenções de Haussmann em Paris. Para Cunha Filho (1998):

[...] Esta é uma constatação histórica que pode ser percebida desde os primeiros melhoramentos: uma das conseqüências mais visíveis das modernas intervenções na cidade tem sido o progressivo afastamento dos pobres dos centros urbanos. (CUNHA FILHO, 1998, p. 153 e 154)

Este processo levou a uma racionalização dos traçados da cidade, que antes tinha como base uma relação mais atrelada ao meio natural, e que não correspondia às necessidades, tal como indica OBA (1998):

Desejável seria aquela legibilidade mais concreta, não necessariamente explícita, capaz de fazer perceber a substância e o significado de cada elemento que compõe o espaço da cidade [...]. Não se pensava mais em um desenvolvimento sedimentar da cidade através de construções que iam 
formando as ruas.[...]. Pensava-se agora, em planos globais.[..]. O aumento acelerado de automóveis, o desenvolvimento do mercado imobiliário, a necessidade de grandes obras sanitárias para preparar essa expansão urbana [..].(OBA, 1998, p. 219)

A Curitiba encontrada por Agache era muito diferente da cidade tal qual a conhecemos hoje. Segundo o próprio urbanista, não passava de um aglomerado de casas, com ar provinciano e que em nada lembrava uma capital. Nas palavras do urbanista para a imprensa:

É uma cidade agradável, mas sem caráter definitivo, possui largas avenidas e ruas aprazíveis, mas que se cruzam geralmente em ângulo reto, num traçado mais ou menos em xadrez, sem preocupação de harmonizar-se com a topografia do terreno, nem de aproveitar-se dos recursos que pode proporcionar.

Tive a honra de fazer o plano de urbanização do Rio, cujo traçado teve em mira o progresso da cidade num espaço de cem anos. E Curitiba também necessita atender a esse particular, porque, com o desenvolvimento que está tendo, dentro de poucos anos viria a lutar com o grave problema do espaço vital, resignando-se à asfixia. Mas, a sua situação comporta um plano largo, de grandes será uma das maiores e mais lindas do Brasil. (DIÁRIO DA TARDE, 1940 , s.p.).

As ruas se assemelhavam a vielas medievais (CORNELSEN, 2010) e todo o sistema de esgotos, transportes e demais serviços em geral eram considerados caóticos. A despeito de seu Plano de Avenidas ter obtido mais êxito, assim como o zoning, Agache fez várias propostas para os sistemas "digestivo" (sistema de esgoto e circulação da água) e de "respiração" (parques etc.) da cidade.

Um novo sistema de esgotos e circulação de água encanada teria que ser pensado e a cidade deveria manter áreas verdes em bom estado de preservação, protegidas pelos poderes públicos, que oferecessem qualidade de vida e espaços para o ócio da população. Algumas áreas presentes no plano realmente foram transformadas em parque, sendo indicativos de como o Plano Agache foi reapropriado mais tarde, pelos novos planejadores da cidade.

Agache definia a Curitiba da época como o entroncamento de alta relevância, donde se irradia a circulação econômica para o interior do estado e sul do país (BOLETIM PMC, 1943). Também descreveu a importância da cidade na defesa nacional, da vida comercial e social, sendo também um importante centro educativo e cultural, decorrente da presença da Universidade do Paraná, atual UFPR (Universidade Federal do Paraná).

Como dito, o plano proposto identificava três grandes problemas urbanos a serem enfrentados: saneamento, descongestionamento e a necessidade de órgãos funcionais. Segundo Agache: 
Pelo que observei, a sua cidade sofre de prisão de ventre. Na vida de uma cidade temos que considerar 3 coisas: circulação (ruas e avenidas); respiração(praças e jardins); e digestão(esgotos). Este detalhe, no momento, talvez, seja o mais grave, por isso que daí podem resultar graves consequências para a saúde pública (DIÁRIO DA TARDE, 1940, s.p.)

A questão do saneamento visava conter as epidemias, causadas pelas enchentes frequentes dos rios Belém e Ivo, os quais seriam canalizados, bem como os demais córregos que cruzavam a cidade. Ambos os rios, foram os primeiros referenciais naturais da cidade, limitando a expansão urbana.

Curitiba teve seu início na encosta de um dessas elevações, hoje a praça Tiradentes; desenvolveu-se em torno dessa atual praça, e nas margens dos antigos caminhos de penetração(Ponta Grossa e Mafra) e no caminho para o mar(Paranaguá e Antonina). Teve assim que se estender pelos vales dos rios e riachos que limitavam a elevação (os rios Ivo e Belém) e daí o sério problema que ainda hoje preocupa: as constantes e nocivas inundações de muitas áreas edificadas e centrais da cidade. (BOLETIM PMC, 1943, p. 11)

Segundo Agache, a cidade evoluindo, criaria o problema do congestionamento. Para solucionar o problema, propôs o alargamento da Rua XV de Novembro. Agache considerou a Rua XV de Novembro o eixo principal da cidade, contudo a considerava muito estreita para a função que desempenhava. Além do alargamento da Rua XV, elaborou o Plano das Avenidas, o qual estava fortemente vinculado à questão da qualidade no transporte coletivo, sendo que este deveria obedecer à distribuição demográfica existente na cidade.

O Plano também considerava a conurbação, a ideia de cidades-satélites, "uma forma moderna de extensão das cidades" (BOLETIM PMC, 1943). Dentre os núcleos² mais desenvolvidos ao redor da cidade, Agache identificava os de Santa Felicidade (atual bairro de Curitiba) e Colombo (município integrante da RMC- Região Metropolitana de Curitiba). A estrutura viária proposta, integrou as diversas colônias e paróquias, criando bairros com características próprias, porém interligados.

Também o Setor Histórico viria a sofrer mudanças, pois era visto como um "redutor de desenvolvimento", fator pelo qual, inúmeros patrimônios foram destruídos, e os que restaram foram relegados ao esquecimento durante anos.

O Plano de Urbanização apresentava detalhamentos técnicos, desenhos e diretrizes gerais à iniciativa pública e também considerava os efeitos dos investimentos públicos. Avançado para a época em que foi elaborado, o Plano de Urbanização de Curitiba foi se desatualizando. Algumas ideias permaneceram como as

\footnotetext{
2 Nas palavras de Garcez (2006): "As colônias agrícolas, distribuídas pelos espaços vazios do planalto curitibano, foram sendo absorvidas progressivamente mais tarde pelos bairros da cidade". (GARCEZ, 2006, p. 21).
} 
avenidas perimetrais e de irradiação estabelecendo a interligação entre os centros funcionais ainda que de forma descontínua e irregular. As obras eram executadas por etapas abrangendo trechos de vias "prioritárias" para resolver os problemas de tráfego e comunicação e os cidadãos que viviam fora de áreas atingidas por obras municipais, insistiam em reivindicar melhoramentos para seus bairros. (SILVA, 2000, p. 216). Todos estes problemas, para Cunha Filho (1998), eram

[...] a visão do corpo, fruto do biologismo interiorizado pela ideologia da modernização, também [...] estendida ao símbolo máximo da civilização: a cidade. Nela, tudo que era tido como "atraso", ao contrário a civilidade e ao "progresso", era identificado como "doença". Foi precisamente neste ponto que se deu o aparecimento dos chamados "problemas urbanos" em Curitiba. "Problemas" esses que, até não muito tempo atrás, ou não se configuravam desse modo ou não eram percebidos como tal (CUNHA FILHO, 1998, p. 89)

A complexidade dos problemas de legislação e administrativos deixaram o plano paralisado durante anos, fazendo com que entrasse em obsolescência por falta de acompanhamento e atualização. O pensamento urbanístico criado desapareceu e o contexto histórico do desenvolvimento da cidade era outro, passou a ser influenciado de forma mais enfática pelas transferências de renda da agricultura, ocupação das terras no norte do Estado e criação de uma malha viária de penetração e integração. (SILVA, 2000, p. 218)

O plano de Curitiba expressava princípios para que a cidade fosse remodelada e atingisse o objetivo de possuir uma representatividade própria, para ser interpretada como uma sociedade integrada no processo de desenvolvimento econômico que se processava em nível de país. A Prefeitura, com a aprovação da lei que estabeleceu o plano viário da cidade, direcionou as obras em função do Plano das Avenidas, procurando reservar áreas para os projetos do plano como o Cemitério-Parques, o Jóquei Clube, a Vila Operária, o Estádio e o Mercado Municipal. As atividades da Prefeitura estavam compreendidas na área central e o Plano de Urbanização aprovava essa localização, sugerindo a construção de nova sede. O centro administrativo, não teria relação com a área do Centro Cívico, ou seja, a prefeitura teria sua sede na atual Praça Tiradentes, enquanto o poder estadual estaria concentrado naquele bairro (DUDEQUE, 2010), o que significava a permanência de uma dinâmica da produção do espaço urbano, da urbanização e dos grupos sociais que se beneficiavam das melhorias e equipamentos. A remodelação para Agache era colocar as coisas em ordem, ou seja, a pesquisa e a organização dos elementos de uma aglomeração urbana. Elementos que se referem à produção e circulação do valor, baseados no modo de exploração do capital e do trabalho. (SILVA, 2000, p.90) 
A confecção do Plano Agache para Curitiba trouxe como maior novidade o zoning, a criação de áreas com grande especificidade, com destaque para o Centro

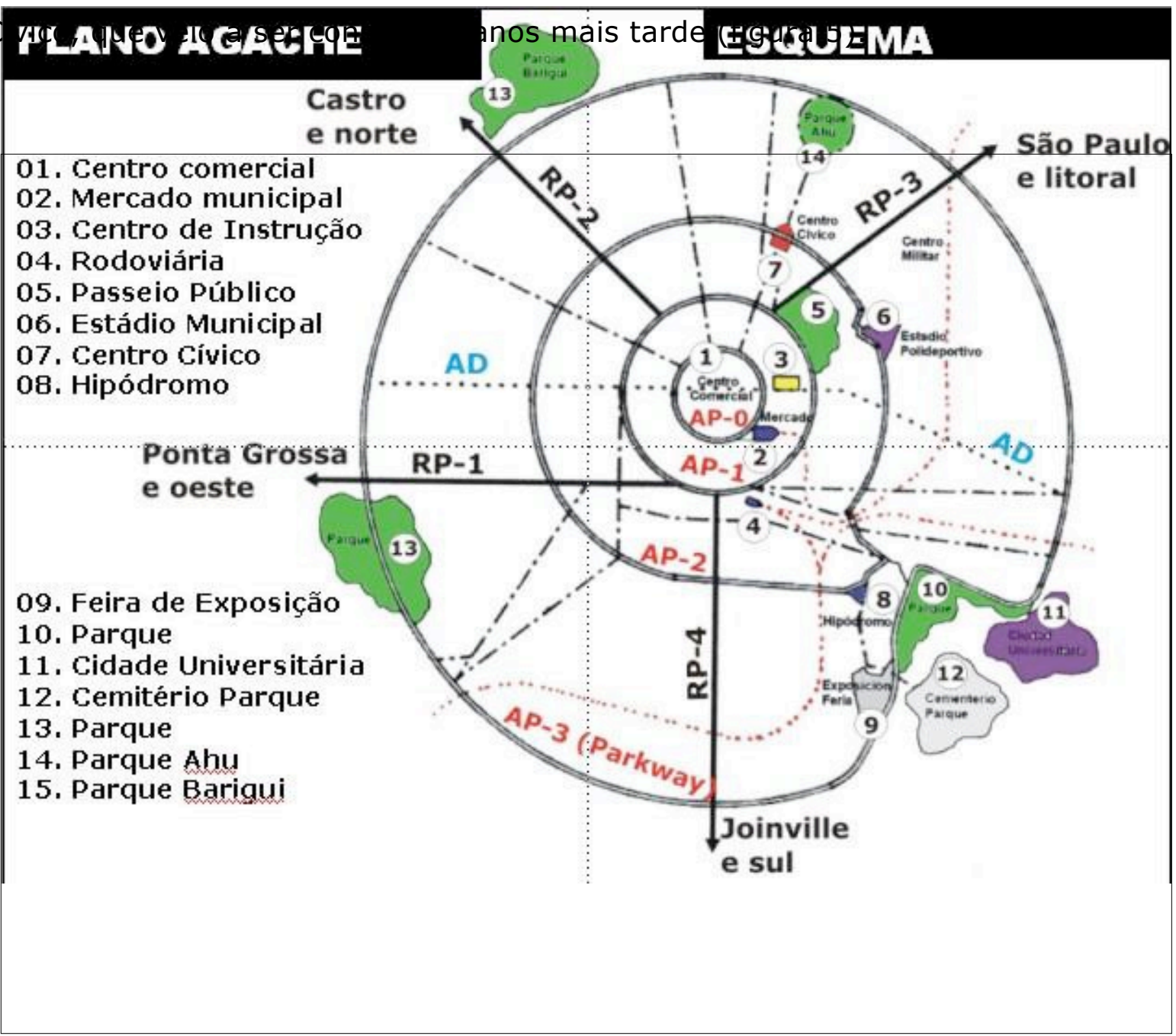

Figura 3: Esquema do Plano Agache (1943)

Fonte: CORNELSEN, 2010

Segundo o urbanista "o zoneamento é base de todo o plano de urbanização e o plano das avenidas como foi concebido, em linhas circulares concêntricas muito facilita o estabelecimento das zonas" (BOLETIM PMC, 1943, p. 56). No entanto, este zoneamento aceitou uma ocupação existente e não direcionou o crescimento. Considerou uma cidade ocupada por população de alto poder aquisitivo, desconsiderando a hipótese de população de renda baixa. (GNOATO, 1997, p. 25)

Para o urbanista, a concentração apresentava vantagens. Agache via no agrupamento o único meio de economia para o transporte de mercadorias e pessoas, e o modo de melhorar as condições de higiene e de salubridade das áreas residenciais e comerciais. Para ele a importância do zoneamento se impunha por si só. Cada bairro tinha função determinada, fosse negócios, comércio, residência ou indústria, merecendo regulamento especial. Existiam áreas onde o problema da desvalorização 
poderia ser corrigido com o zoneamento. As zonas disporiam de regras para volume, altura e a característica dos prédios, se permitindo a densidade máxima nos terrenos mais caros e zonas residenciais, para evitar a subdivisão dos lotes, gerando alta dos preços e especulação (SILVA, 2000, p. 74).

Agache propunha um zoneamento que assegurasse melhores condições de salubridade e tranquilidade, respondendo às necessidades de trabalho e moradia. 0 urbanista foi conservador quanto aos resultados das modificações na economia de cada bairro, reajustes e atualizações de preços da terra ou desvalorizações, além dos conflitos entre interesses públicos e privados. (SILVA, 2000, p. 65) O plano foi a primeira experiência de planejamento urbano nascida de uma decisão política para intervir na ordenação, embelezamento e remodelação com ajuda dos progressos da técnica e da ciência. A aceitação das novas ideias implicava na nova forma de solução para os problemas da cidade. A imprensa, os representantes de classes e os governos municipal e estadual difundiram o que era representado como interesse comum. 0 plano transformava a realidade não desejada, otimizando as condições de vida.

Divulgava a imprensa:

Curitiba antiga, Curitiba moderna, atual e Curitiba de amanhã... não fora a certeza dos milagres que a arquitetura opera ao serviço de homens de talento... quando for, enfim uma realidade o grande e incomparável plano de remodelação e transformação ideado e traçado pelo famoso urbanista Agache, sob a inspiração do ilustre Prefeito Rosaldo Leitão.... futuro da cidade depende da execução do plano...(Diário da Tarde, 1942, p.1)

A cidade como centro dos capitais impõe a divisão do trabalho e a especialização como condição para seu desenvolvimento. Para Agache a vida urbana gravita em torno de elementos funcionais especializados, organizados no espaço para facilitar as relações entre eles e as aglomerações, cujas proporções se dariam com base na densidade da população da superfície para cada função, circulação e para as extensões e desmembramentos. Suas propostas para mudar condições relacionadas ao zoneamento criando ideias da separação são universais e buscavam atender aspirações e necessidades de uma sociedade estratificada. Ele disse que o zoneamento atingiria os resultados esperados caso estivesse ligado ao aspecto social dos problemas da cidade, ou seja, o da habitação. Agache não colocava o zoneamento como instrumento segregador negativo, mas sim uma forma de harmonizar as construções e as necessidades de seus ocupantes dentro do território urbano separando áreas comerciais, industriais e residenciais com diferentes densidades que conduzissem ao que ele chamou de uma "figura urbana ideal". (SILVA, 2000, p. 82)

As propostas do Plano Agache para Curitiba demonstram a preocupação em se 
modernizar a cidade, um Urbanismo que, como em diversas partes do mundo, se desenvolveu como filho da modernidade, calcado sobretudo na mobilidade e na setorização da cidade. A possibilidade da modernização se expressa nos planos, tendo a cidade como objeto de sua intervenção, através de mecanismos de regulação que influíam sobre as condições de vida da população, mesmo considerando a ênfase nos aspectos relativos às reformas nos centros urbanos. Nas palavras de Ribeiro e Cardoso (1996) "a relação dos planos com a efetiva regulação pública não se efetiva. Os planos produzem normas destinadas a não serem cumpridas, criando assim um abismo entre a 'cidade real' e a 'cidade legal'". (RIBEIRO e CARDOSO, 1996, p. 64 e 65).

Para Agache, tanto a lei que aprovaria o plano quanto a que aprovasse o zoneamento, para responderem aos seus objetivos, deveriam ter continuidade e para isso, deveriam estar alheias às inconstâncias políticas. Condições preconizadas no texto do Plano de Urbanização de Curitiba, mais tarde utilizadas no relatório da SAGMACS ${ }^{3}$ e culminando na criação do IPPUC ${ }^{4}$, em 1965.

Segundo Agache (1930), para a materialização de um plano urbanístico, era necessário o levantamento histórico do território, o qual no caso de Curitiba foi realizado de maneira sucinta, não relatando, como o plano do Rio de Janeiro, todas as transformações urbanas. Nestas breves considerações sobre a passagem de uma fase de urbanização para outra, o urbanista coloca em evidência as implicações sobre o espaço urbano e a geografia, em especial a geomorfologia e a hidrografia da região.

Para o plano que Agache confeccionou em 1930 destinado a remodelar a capital federal do Brasil, ele estudou a situação particular do desenvolvimento da cidade através dos séculos, antes de propor os princípios do Urbanismo aplicados à higiene, a circulação e a estética para seu desenvolvimento futuro. A evolução urbana estava retratada na dinâmica dos fatores topográficos, econômicos e sociais reveladores do esforço de seus habitantes para ajustar a natureza às circunstâncias da vida, marcada principalmente, por suas conotações culturais e sociais.

Agache deu início ao esboço histórico do plano carioca pela fundação da cidade mostrando o surgimento dos fatos urbanos pontuados pelas características do uso que os moradores fizeram dos acidentes geográficos e do solo, pois um plano precisaria destacar as características de um centro urbano comercial, industrial, residencial,

\footnotetext{
${ }^{3}$ Sociedade de Análises Gráficas e Mecanográficas Aplicadas aos Complexos Sociais, sociedade com orientação de Louis Joseph Lebret, que durante as décadas de 1950 e 1960 desenvolveram estudos sobre planejamento urbano e regional no Paraná e em outros estados brasileiros.
} 
universitário, de trânsito, para só depois estabelecer as diretrizes e a localização das zonas no espaço físico-territorial (OBA, 1998). Portanto, para o plano destinado a remodelar a capital federal do Brasil, estudou a situação do desenvolvimento da cidade antes de propor os princípios aplicados à higiene, à circulação e à estética. Esse aspecto metodológico foi introduzido no Plano de Urbanização de Curitiba de forma a evidenciar as implicações entre espaço urbano e geografia. (SILVA, 2000, p.71)

A cidade para Agache poderia ser definida da seguinte maneira: a grande cidade seria o centro nervoso, o cérebro de toda uma região e às vezes, de um país, onde ocorrem todos os tipos de conflitos, entre o social, o econômico e o político (BOLETIM PMC, 1943). Por isso, os contatos deveriam ser imediatos, mão a mão. Quando isso não ocorre, nasce a congestão. Era o caso de Curitiba, analisado por ele. Os estudos de um plano exigiam do urbanista prudência quanto à transformação de uma cidade e sua extensão. Agache julgava poder impor regras, estabelecer zonas e posturas, cabendo à municipalidade aplicá-las em parte ou criar uma comissão para mostrar aos proprietários que elas não restringiram seu direito, mas criaram valores para o conjunto das propriedades. A limitação da extensão era indispensável para delimitar o alcance dos serviços públicos. Contudo, nem sempre os limites administrativos correspondiam aos reais das aglomerações. Para Curitiba, o Plano de Urbanização estabeleceu limites para a extensão da cidade apesar da existência de loteamentos e aglomerações fora de seu perímetro, sendo que uma solução era transformá-las em cidades satélites.

O urbanista se preocuparia com espaços que já não eram mais de passeio ou embelezamento, mas elementos da higiene e aspecto urbano. A higiene da cidade se faria através de reservatórios de ar puro. Os parques, os campos, as reservas florestais, os jardins, as avenidas arborizadas e os parkways deveriam ser previstos pelo plano conforme a densidade de habitantes. Curitiba tinha espaços suficientes, porém mal distribuídos, alegava o plano. Quanto aos parques, a cidade estava privada de reservas. (SILVA, 2000, p. 73)

A organização da circulação foi concebida com base em princípios da Carta de Atenas, (AUZELLE, 1953, p. 90) entre eles, o de dar a cada via uma destinação - para automóveis, transporte de carga, pedestres -, dimensões e características especiais. 0 que acontecia no centro era que as ruas estavam dispostas em pequenas quadras, engarrafando, sem nenhuma especialização para que o tráfego fosse confluente ou

\footnotetext{
${ }^{4}$ O IPPUC foi criado como uma Autarquia Municipal, ampliando a área de atuação da APPUC, que teve duração de apenas 122 dias (DUDEQUE, 2010).
} 
divergente. O critério para definir as particularidades das vias, baseado no escoamento e no tipo de veículo, tinha quatro finalidades: priorizar o automóvel, compreendendo sua circulação de trânsito e os acessos de entrada e saída da cidade; tangenciar a cidade, que servia aos veículos de tráfego pesado; a ligação entre bairros, fossem eles institucionais, residenciais, comerciais ou industriais e por fim um sistema complementar de vias para tráfego local ou passeios, um sistema viário básico. (SILVA, 2000, p. 76)

O processo de expansão da cidade se caracterizou pela verticalização. A ação dos empresários na construção de edifícios foi favorecida pelos avanços tecnológicos no sistema construtivo, como o concreto armado. Curitiba era o centro da vida intelectual do Estado, concentrando escolas de nível superior e médio para atender estudantes da cidade e de outros estados. Os engenheiros que, até a década de 1930, atuavam mais pontualmente na construção de estradas, de edifícios públicos, nos cargos públicos, na política e na colonização de cidades, começavam a concentrar seus esforços na construção civil dentro do perímetro urbano. (SILVA, 2000, p.13)

Para Agache, o plano deveria conseguir melhoramentos sem prejuízo da estética, oferecendo conforto e segurança aos habitantes, inovando, mas conservando. Os princípios do urbanismo também atingiam as zonas residenciais nos bairros principais (Juvevê, Bacacheri, Glória, Água Verde, Assungui, Bigorrilho, Mercês, Guabirotuba, Cajuru, Ahú e Batel) e ruas, praças e avenidas, para estabelecer comunicação entre eles. Nesta época, existiam em Curitiba cerca de 16.700 prédios e poucas ruas eram trabalhadas. O mercado imobiliário investia nas regiões onde o poder público já havia urbanizado, sobretudo nas áreas pavimentadas. (SILVA, 2000, p. 63) A repartição da população no espaço estava em função dos caracteres linguísticos e culturais e das circunstâncias financeiras de cada um. Era comum grandes áreas pertencerem a herdeiros, que mais tarde transformaram-nas em loteamentos.

O plano foi apresentado como um conjunto de ideias, de procedimentos e de valores, desencadeando um processo de tomada de decisão afastada da participação da população e segundo uma visão limitada à dos planejadores. (SILVA, 2000, p. 65) Para normalizar a administração tributária, a Prefeitura aprovou em 1942 o Plano de Avenidas da Cidade, base para delimitar os quadros urbano e suburbano, iniciando os estudos do Código de Obras e do Tributário.

O financiamento para o plano foi aprovado pelo Decreto Municipal n. 7 de 1942, que descreve como seria aplicado o empréstimo contraído junto à Caixa Econômica Federal no Paraná. A repartição feita mostra que a política urbana não 
estimulava as atividades do planejamento para ordenar o crescimento da cidade. 0 valor financeiro era muito inferior ao valor para desapropriações e indenizações, bem como para a implantação de obras definidas pelo plano, concentradas, sobretudo, nas áreas contíguas ao Centro Histórico para onde se conduzia a expansão urbana das classes médias (Alto da Glória, Juvevê, Água Verde, São Francisco e Centro). (SILVA, 2000, p. 44)

Este plano não foi integralmente implantado, mas foi sobre muitas de suas marcas que o novo Plano Diretor, anos mais tarde, foi desenvolvido. O ponto essencial do Plano de Urbanização de Curitiba (nome oficial do comumente denominado Plano Agache) era constituído de cinco esferas de ação que assegurariam a reprodução do capital assim listadas: o Plano das Avenidas da Cidade, os centros funcionais, o código de obras e zoneamento, os espaços livres e reservas de áreas e a extensão da cidade, com intenção de intervir no espaço físico-territorial (BOLETIM PMC, 1943). Conforme destaca OBA (1998), a imagem da cidade moderna, impulsionada pela difusão do capitalismo, sobretudo nas capitais, evidenciava uma nova definição para suas funções, fossem elas de comando, de produção, de consumo ou sociais.

Elaborado em dois anos (1941-1943), o plano foi entregue na gestão do prefeito Alexandre Beltrão. Devido a problemas econômicos e ao intenso crescimento da cidade, o plano não teve o sucesso esperado. Dele restaram, no entanto, as grandes avenidas, como a Visconde de Guarapuava, Marechal Floriano Peixoto e Sete de Setembro; as galerias pluviais da Rua XV de Novembro; o recuo obrigatório de cinco metros para novas construções; a Zona Industrial, atrás da Estação Ferroviária; a previsão de áreas para o Centro Cívico (bairro sede dos governos estadual e de diferentes tribunais e órgãos do poder público) e o Centro Politécnico (atual campus da Universidade Federal do Paraná); bem como o Mercado Municipal (BOLETIM PMC, 1943).

Segundo o relatório SAGMACS (1963, apud Garcez, (2006), as causas da falta de sucesso do Plano Agache foram as seguintes:

1 - plano restrito à área urbana, sem considerar o território do município;

2 - plano concebido dentro de um espaço geométrico, exigindo um controle rígido do crescimento da cidade;

3 - a especulação imobiliária provocou loteamentos excessivos, estendendo a cidade muito além do Plano de Avenidas;

4 - A Constituição de 1946 obrigava o pagamento imediato e em dinheiro das desapropriações ou a liberação do uso que convier ao proprietário, impossibilitando a prefeitura a fazer frente à

quantidade de áreas a desapropriar. (GARCEZ, 2006, pg. 75)

Na década de 1950, segundo Ferreira (2004), o Paraná, ainda sofria forte 
influência do que fora a principal característica política - centralização do poder - do Estado Novo (1930-1945) comandado por Getúlio Vargas. Este período foi marcado por imponentes projetos, públicos, pois assim como fora importante para o urbanismo curitibano, a década também o foi para o restante do país, passando a se pensar em construções arrojadas que marcassem a passagem para a modernidade. (FERREIRA, 2004, p. 26)

Quando em 1951 chegou ao poder Bento Munhoz da Rocha Netto, a cidade já possuía uma nova aparência e ele colocou em prática ideias contidas no plano de Agache e modernistas de Le Corbusier. Um exemplo foi a construção do Centro Cívico, em espaço sugerido pelo Plano Agache, mas com edifícios de forte expressão modernista, elaborado por David Azambuja e sua equipe, discípulos de Le Corbusier e Oscar Niemeyer (DUDEQUE, 2010). Segundo Ferreira (2004), os antigos moradores de Curitiba, entrevistados por ele, reconhecem que o "governador Bento" iniciou a transformação de Curitiba no que ela é hoje com as obras inauguradas por ocasião das comemorações do centenário de emancipação. Assim, Santos (1999) afirma que o ano do Centenário era o momento em que a maioria dos que viveram aquele tempo reconhecem ser como o do início da transformação urbana de Curitiba.

A Curitiba de ontem ficava para trás e, a Curitiba de hoje, "cidade com uma infraestrutura razoavelmente bem estabelecida", estava sendo fundada em 1953, "momento que assinala uma reorganização do seu espaço urbano. O tempo que se inaugurava, e que ainda permanece [..] será percebido como um tempo de expansão física e populacional da cidade" (SANTOS, 1999, p. 69).

Para Santos (1999) "Se nada soubéssemos a respeito de Curitiba [..] poderíamos imaginar que a cidade brasileira 'de primeiro mundo', num momento qualquer, apareceu do nada e instalou-se no sítio que ela agora ocupa", pois é recorrente a afirmação de que Curitiba "começou" nos anos de 1970; "no entanto, essa cidade de pouco mais de 30 anos (período pós-1970) é apenas uma das muitas Curitibas que podem ser reconhecidas. Mais exato seria dizer - ou entender - que a partir de 53 que começou, assim, o desenvolvimento de Curitiba" (SANTOS, 1999, p. 57, grifo no original), pois, a partir de 1953, é possível dizer que se assistiu a uma refundação da cidade, devido ao planejamento contínuo implantado. Segundo o autor, "alguns traços do passado de uma cidade ficam evidentes a qualquer transeunte: usualmente, são as inscrições produzidas por atos de governantes, monumentos que se constituem em documentos de uma história oficial" (SANTOS, 1999, p. 63), pois

Estranhamente, uma série de rupturas e descontinuidades no espaço é que representa a continuidade do tempo. À própria cidade confere-se um caráter 
de monumento. Um monumento que pode ser lido como um documento texto que permite realizar uma interpretação dos processos de sua produção. (AUGÉ, Marc. apud SANTOS, 1999, p. 63, grifos no original)

O autor, que trabalhou com depoimentos, coloca que é "praticamente impossível separar, nos depoimentos, a cidade daquele tempo e o bonde. Os bondes integravam-se à paisagem da cidade, suas linhas cortavam Curitiba de norte a sul e de leste a oeste. Pode-se afirmar que a Curitiba de ontem só se estendia onde tinha a linha do bonde [..]". (SANTOS, 1999, p. 73, grifos no original). Ao diferenciar "fases" no processo de transformações urbanas, o autor expõe que "as diferentes 'fases' que Curitiba parece expor para os seus habitantes é o que permite perceber a dinâmica da expansão da área urbanizada da cidade" (SANTOS, 1999, p. 82), significando uma crescente independência dos bairros e o paulatino desaparecimento do Centro como elemento aglutinador da vida da cidade (SANTOS, 1999).

Portanto, "as principais características que a expansão da cidade apresenta estão relacionadas à sua dinâmica populacional e às ações urbanísticas que visavam solucionar os problemas urbanos daí decorrentes" (SANTOS, 1999, p. 87), visto que a população atual representa mais de dez vezes o número de habitantes existente em 1950 e, se considerarmos a Região Metropolitana de Curitiba (RMC), esta relação passa a mais de vinte vezes, sendo que as pessoas não se distribuíram em proporções iguais pelo espaço da cidade, evidenciado no forte adensamento populacional no crescimento vertical de Curitiba.

A despeito de todos os seus problemas e dos aspectos que caracterizam sua dinâmica de crescimento, Curitiba passou a ser vista como um exemplo de cidade após a década de 1970, mesmo em âmbito internacional. Esta condição motivou nos últimos anos a realização de diversos estudos que procuram discutir as condições que proporcionaram a Curitiba tornar-se uma cidade exemplar nas soluções de seus problemas urbanos (SANTOS, 1999), e hoje, muitas das indagações sobre este aparente sucesso estão em geral impressos e divulgados, sejam eles o planejamento urbano, o marketing político ou outros, que, possivelmente, seriam respostas que explicariam a bem-sucedida experiência do planejamento em Curitiba.

\section{Referências}

AGACHE, D. La Remodelation d'une capitale. Aménagement, extension, embelissement; Paris, Societé cooperative d'architectes, 1932, p. XVIII, v. 1 
BRUANT, Catherine. Donat Alfred Agache: urbanismo uma sociologia aplicada. RIBEIRO, Luiz Cesar de Queiroz Ribeiro. PECHMAN, Robert (org.) Cidade, povo e nação. Gênese do urbanismo moderno. Rio de Janeiro, Civilização Brasileira, 1996. p. 167 a 202.

BOLETIM PMC. Plano de Urbanização de Curitiba. Curitiba, novembro/dezembro, ano II, n. 12, 1943. 136 p.

CUNHA FILHO, Valter Fernandes da. Cidade e Sociedade: A gênese do urbanismo moderno em Curitiba (1889 - 1940). Dissertação (Mestrado em História) Programa de Pós-graduação em História. UFPR, Curitiba, 1998.

DUDEQUE, Irã Taborda. Nenhum dia sem uma linha: uma história do urbanismo em Curitiba. Studio Nobel, São Paulo, 2010, 429 p.

FERREIRA, Luciana. A importância da relação entre a arte pública e a cidade: uma análise dos murais de Poty Lazzarotto. Dissertação (Mestrado em Comunicação e Linguagens). Programa de Pós-graduação em Comunicação e Linguagens Universidade Tuiuti do Paraná. Curitiba, 2004. 80 p.

GARCEZ. Luiz Armando. Curitiba - Evolução Urbana. Rio de Janeiro, Curitiba, 2006. $168 \mathrm{p}$.

GNOATO, Luís Salvador Petrucci. Introdução do ideário Modernista na Arquitetura de Curitiba.(1930-1965). São Paulo, 1997. Dissertação (Mestrado em Arquitetura e Urbanismo) Faculdade de Arquitetura e Urbanismo. Universidade de São Paulo.

OBA, Leonardo Tossiaki. Marcos urbanos e a construção da cidade: a identidade de Curitiba. São Paulo, 1999. Tese (Doutorado em Arquitetura e Urbanismo) Faculdade de Arquitetura e Urbanismo. Universidade de São Paulo.

PEREIRA, Margareth da Silva. Pensando a metrópole moderna: os planos de Agache e Le Corbusier para o Rio de Janeiro. In: RIBEIRO, Luiz Cesar de Queiroz Ribeiro. PECHMAN, Robert (org.) Cidade, povo e nação. Gênese do urbanismo moderno. Rio de Janeiro, Civilização Brasileira, 1996. p. 363 a 376

SANTOS, Antonio Cesar de Almeida. Memórias e cidade; depoimentos e transformação urbana de Curitiba (1930-1990). Ed. Aos Quatro Ventos, Curitiba, 1999, $2^{\text {a Ed. }}$

SILVA, Maclôvia Corrêa da. O Plano de urbanização de Curitiba - 1943 a 1963 e a valorização imobiliária. FAU/USP, 2000. Tese (Doutorado) - Faculdade de Arquitetura e Urbanismo. Universidade de São Paulo. 